\title{
Effectiveness of exercise on cognitive impairment and Alzheimer's disease
}

This article was published in the following Dove Press journal:

International Journal of General Medicine

23 May 2013

Number of times this article has been viewed

\author{
Sandor Balsamo ${ }^{1-4}$ \\ Jeffrey MWillardson ${ }^{5}$ \\ Frederico Santos de \\ Santana ${ }^{1-4}$ \\ Jonato Prestes ${ }^{6}$ \\ Denise Coscrato Balsamo ${ }^{4}$ \\ Dahan da Cunha \\ Nascimento ${ }^{3-6}$ \\ Leopoldo dos Santos- \\ Neto ${ }^{1,2}$ \\ Otávio T Nobrega' \\ 'Graduate Program in Medical \\ Sciences, School of Medicine, \\ University of Brasília, ${ }^{2}$ Rheumatology \\ Division, University of Brasília \\ Hospital, ${ }^{3}$ Department of Physical \\ Education, Euro-American University \\ Center, ${ }^{4}$ GEPEEFS (Strength Training \\ and Health Research Group), \\ Brasília, Brazil; ${ }^{5}$ Kinesiology and \\ Sports Studies Department, Eastern \\ Illinois University, Charleston, IL, \\ USA; ${ }^{6}$ Graduate Program in Physical \\ Education and Health, Catholic \\ University of Brasilia, Brasilia, Brazil
}

Correspondence: Sandor Balsamo

Graduate Program in Medical Sciences,

School of Medicine, University of Brasília,

Brasília, Brazil 70910900

Tel +55 6I 3107 I70I

Fax +55 6I $3107 \quad 907$

Email sandorbalsamo@gmail.com
Abstract: Physical activity has a protective effect on brain function in older people. Here, we briefly reviewed the studies and results related to the effects of exercise on cognitive impairment and Alzheimer's disease. The main findings from the current body of literature indicate positive evidence for structured physical activity (cardiorespiratory and resistance exercise) as a promising non-pharmacological intervention for preventing cognitive decline. More studies are needed to determine the mechanisms involved in this preventative effect, including on strength, cardiorespiratory, and other types of exercise. Thus, the prevention of Alzheimer's disease may depend on healthy lifestyle habits, such as a structured physical fitness program.

Keywords: randomized controlled trial, memory disorders, healthy lifestyle habits, physical activity

\section{Introduction}

Alzheimer's disease (AD) is a multifactorial and progressive neurodegenerative disease. Aspects of $\mathrm{AD}$, such as increased oxidative state, amyloid plaque deposition, and neurofibrillary tangles of tau protein in the central cortex and the limbic system of the brain, have been associated with the disease. ${ }^{1}$ The incidence of $\mathrm{AD}$ doubles after the age 65 years, with 1.275 new cases diagnosed annually for every 100,000 individuals over the age of 65 . It is expected that the incidence of $\mathrm{AD}$ will continue to rise, impacting both social and economic aspects of the world's health systems. ${ }^{2}$ Therefore, it is imperative that potential prevention and/or treatment strategies are thoroughly researched to prepare medical professionals for an increase in AD cases.

The risk of heart disease, coronary artery disease, type 2 diabetes, some forms of cancer, and all-cause mortality is negatively associated with physical activity. ${ }^{3-5}$ Further, several observational studies have indicated that individuals who are more physically active accrue protective benefits against dementia, especially AD. ${ }^{6,7}$ Thus there is a need to investigate the effectiveness of non-pharmacological prescriptive strategies as regular structured exercise programs for preventing or reversing cognitive impairment as well as attenuating the progression of dementia. Therefore, the purpose of this brief review was to assess from the current body of literature the effects of structured physical fitness programs including cardiorespiratory and resistance exercise on the cognitive response in elderly subjects with AD.

\section{Methods}

For this review, MEDLINE, Google Scholar, IndexCat, PsycARTICLES ${ }^{\circledR}$, and SPORTDiscus $^{\text {TM }}$ databases were searched up to November 2012 using MeSH 
database terminology. The two criteria for the inclusion of articles were: (1) studies retrieved using the controlled keywords "cognitive impairment" or "Alzheimer's disease" combined with (2) studies retrieved on any of the following themes: physical fitness, aerobic exercise, cardiorespiratory fitness, cardiovascular training, aerobic capacity, aerobic conditioning, muscle strength, exercise, exercise training, strength training, resistance training, resistance exercise, performance, exercise capacity, functional capacity, and physical exercise. A survey was taken of the indexed publications in the searched databases. The effects of regular exercise on cognitive responses reported from these studies are summarized in Table 1.

\section{Functional capacity and cognitive decline in AD}

Functional capacity is recognized as a classic marker of cognitive impairment (CI) and AD. ${ }^{8-12}$ For instance, Eggermont et $\mathrm{al}^{13}$ conducted a comparative analysis between three groups: those without CI, those with CI, and patients with AD. They compared functional capacity through the following tasks: $4 \mathrm{~m}$ walk, sitting and standing for 30 seconds, and the timed up-and-go test. The results suggested an inverse association between CI and lower-limb functional capacity.

Several studies ${ }^{8-12}$ have examined differences in the functional capacity of the lower limbs in people with CI and/or adults who were cognitively healthy or had AD;

Table I Studies that reported results with randomized controlled trials involving regular exercise and effects on cognitive responses

\begin{tabular}{|c|c|c|}
\hline Study & Training program, age in years (standard deviation or range) & Results \\
\hline Lautenschlager et al ${ }^{18}$ & $\begin{array}{l}\text { Group I: had } 85 \mathrm{Cl} \text {; trained } 6 \text { months, varied exercises program; } \\
\text { I } 50 \text { min per week or I0,000 steps/day - age: } 68.6(8.7) \\
\text { Control group: had } 85 \mathrm{Cl} \text {; daily living activities - age: } 68.7(8.5)\end{array}$ & Group I: ADAS-Cog $=$ NS \\
\hline Baker et al ${ }^{19}$ & $\begin{array}{l}\text { Group I: had } 23 \mathrm{Cl} \text {; trained } 6 \text { months walking, } 75 \% / 85 \% \text { MHR } 4 \text { days } \\
\text { week; } 45 / 60 \text { min - age: } 70.0 \text { (8.5) } \\
\text { Control group: had I0 Cl; did stretching - age: } 68.7(8.5)\end{array}$ & $\begin{array}{l}\text { Group I: executive } \\
\text { activities = @ } \\
\text { (only in women) }\end{array}$ \\
\hline Rolland et $\mathrm{a}^{20}$ & $\begin{array}{l}\text { Group I: had } 67 \text { AD; trained } 6 \text { months, varied exercises } \\
\text { (not reported); } 3 \text { days week; } 60 \text { min - age: } 83 \text { (62-103) } \\
\text { Control group: had } 67 \text { AD; daily living activities - age: } 83 \text { (62-103) }\end{array}$ & Group I: MMSE $=$ NS \\
\hline Hernandez et $\mathrm{a}^{21}$ & $\begin{array}{l}\text { Group I: had } 9 \text { AD; trained } 6 \text { months, varied exercises, } 60 \% / 80 \% \\
\text { FCM; } 2 \text { days week; } 60 \text { min - age: } 78.5(6.8) \\
\text { Control group: had } 7 \text { AD; daily living activities - age: } 78.5(6.8)\end{array}$ & $\begin{array}{l}\text { Group I: MMSE = NS } \\
\text { Control: significant decline } \\
\text { in MMSE compared with the } \\
\text { baseline }\end{array}$ \\
\hline Liu-Ambrose et $\mathrm{a}^{28}$ & $\begin{array}{l}\text { Group I: had } 52 \mathrm{El} \text {; strength training; } 6 \text { months, } 2 \text { days week; } \\
6 / 8 \text { reps; } 2 \text { sets; } 60 \text { min - age: } 69.4 \text { (3.0) }\end{array}$ & $\begin{array}{l}\text { Group I and 2: executive } \\
\text { cognitive activities = @ }\end{array}$ \\
\hline
\end{tabular}

Group 2: had $54 \mathrm{El}$; strength training; 6 months, I day week;

6/8 reps; 2 sets; $60 \mathrm{~min}$ - age: 69.5 (2.7)

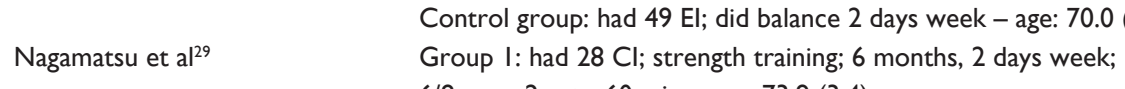

6/8 reps; 2 sets; 60 min - age: $73.9(3.4)$

Group 2: had $30 \mathrm{Cl}$; cardiorespiratory training; 6 months,

2 days week; $70 \% / 80 \%$ HRR; 60 min - age: 75.6 (3.6)

Control group: had $28 \mathrm{Cl}$; did balance 2 days week - age: 75 (3.6)

Cassilhas et $\mathrm{a}^{26}$

Group I: had $20 \mathrm{El}$; strength training; 6 months, 3 days week;

$80 \%$ I RM; 2 sets; 60 min - age: $67.0(0.5)$

Group 2: had $19 \mathrm{El}$; strength training; 6 months, 3 days week;

50\% I RM; 2 sets; 60 min - age: 69.0 (I.I)

Control group: had $23 \mathrm{El}$; did stretching I day week - age: 68.4 (0.6)

Venturelli et al ${ }^{14}$

Group I: had II AD; 4 months of walking, moderate intensity;

4 days week; $30 \mathrm{~min}$ - age: 83.0 (6)

Control group: had $10 \mathrm{AD}$; daily living activities (bingo/patchwork

sewing/music therapy) - age: 85.0 (6.0)

Group I: executive cognitive activities = @

Group I and 2: ${ }^{\dagger}$ cognitive tests = @

Group I: MMSE = @

Control: significant decline in MMSE (compared with the baseline)

Notes: @, significantly higher average values than the control group; ${ }^{\dagger}$ cognitive tests, Wechsler Adult Intelligence Scale III (similarities: assessing central executive/digit span, forward and backward: assessing short-term memory), Wechsler Memory Scale-Revised (Corsi block-tapping task, forward and backward: assessing visual modality of short-term memory), Toulouse-Piéron's concentration attention test - assessing attention, and Rey-Osterrieth complex figure (form A - Rey figure and form B - Taylor alternative version) assessing long-term episodic memory.

Abbreviations: I RM, one-maximum repetition; AD, Alzheimer's disease individuals; ADAS-Cog, Alzheimer Disease Assessment Scale - Cognitive subscale; Cl, cognitive impairment individuals; El, elderly independent individuals; NS, no significant difference between the groups in the aspects evaluated; HRR, heart rate reserve; min, minutes; MHR, maximum heart rate; MMSE, mini-mental state examination; reps, repetitions. 
however, these analyses have methodological limitations (the use of different study populations, diagnostic criteria, sample sizes, and motor function measurements). Notably, several possible moderating factors can affect the functionality of the lower limbs, such as osteoporosis ${ }^{8,11}$ and parkinsonian signs,,${ }^{9,10,12}$ and these were not uniformly considered in all studies. However, Eggermont et $\mathrm{al}^{13}$ addressed these methodological biases and indicated the extent of physical dysfunction independently associated with CI in their study.

Other studies have shown a greater impairment in lower limb function in individuals with AD compared with controls. ${ }^{8-12}$ Moreover, Venturelli et al ${ }^{14}$ recently investigated the effect of moderate intensity walking on cognitive response and functional capacity in elderly patients with AD. This randomized controlled trial (RCT) indicated that a 4-month walking intervention (moderate intensity) improved the distance covered in the 6-minute walk test (6WT), as well as activities of daily living (ADL) evaluated by the Barthel index. However, scores on the mini-mental state examination (MMSE) decreased 13\% over the intervention period in the experimental group. Nevertheless, the control group (who did not undergo the walking intervention) demonstrated significantly greater decline in all the tests: $-20 \%$ in the $6 \mathrm{WT},-23 \%$ in ADL, and $-47 \%$ in the MMSE. This study reveals the positive effects of a walking program on physical function and in attenuating the decline of cognitive function for $\mathrm{AD}$ patients.

\section{Effect of cardiorespiratory exercise and varied exercise programs on $\mathrm{Cl}$ and $\mathrm{AD}$}

Currently, studies have focused on the effects of cardiorespiratory exercise on symptoms associated with CI. ${ }^{15}$ Possibly due to the inverse relationship between CI and cardiovascular fitness. ${ }^{15,16}$ For example, Burns et al demonstrated that subjects who had higher levels of cardiorespiratory fitness ( $\mathrm{VO}_{2}$ peak) displayed lower levels of brain atrophy. ${ }^{17}$

Some RCTs have evaluated the effect of cardiorespiratory exercise in older adults with AD. Lautenschlager et $\mathrm{al}^{18}$ conducted an intervention in elderly patients for a period of 6 months followed by another 18 months of follow-up, after which they reported no significant difference in cognitive responses - as assessed by the Alzheimer Disease Assessment Scale - Cognitive subscale (ADAS-Cog) and $\mathrm{ADL}$ - between the exercise group and the control group. In another study, Baker et al ${ }^{19}$ evaluated the effect of a 6-month cardiorespiratory exercise intervention and found that improved cardiovascular fitness was accompanied by an increased efficiency in activities - such as executive control processing, multitasking, and efficiency of information processing and selective attention. However, when the results were adjusted for sex, a significant difference occurred only in women with increased oxygen consumption ( $\mathrm{VO}_{2}$ peak) and improvements in cognitive activities.

There are some explanations for the inequality between men and women regarding cognitive improvement in association with exercise. For example, it is speculated that estrogen may have a neuroprotective effect because many women after menopause are on hormone replacement therapy. ${ }^{15}$

Another RCT, which was performed in elderly residential institutions in France, investigated the effect of an exercise program on the ability of AD patients to perform ADLs, physical performance, and of behavioral disturbances and depression. In that study, Rolland et $\mathrm{al}^{20}$ conducted an interventional exercise program for 12 months with 1 hour of exercise twice a week that included walking, exercise, muscle strength, balance and flexibility tasks, while the control group received only traditional health care. The intervention group performed significantly better in the $6 \mathrm{~m}$ walking speed test. However, no effect was observed for cognitive responses.

In a study conducted in Brazil, ${ }^{21} \mathrm{AD}$ patients underwent a varied exercise program for 6 months that included various exercises, circuits, sport dance sequences, recreational activities, stretching activities, weight training, and relaxation. The results indicated that cognitive function (measured using the MMSE) was preserved during the interventional period, while the control group, whose members maintained their routine activities (no exercise), experienced a significant decline in MMSE score.

Another important point, regardless of sex, is that cardiorespiratory training is critical for a patient with $\mathrm{AD}$, especially in the initial phase. ${ }^{22}$ Recently, Middleton et $\mathrm{al}^{24}$ found that women who reported being physically active at any point over their life course had a lower likelihood of $\mathrm{CI}$ in later life.

\section{Effect of strength training on $\mathrm{Cl}$ and $\mathrm{AD}$}

In a cross-sectional study, Petrella et $\mathrm{al}^{24}$ evaluated the relationship between quadriceps muscle strength and CI among frail 
elderly patients and physically independent patients. An inverse correlation was found between muscle power and CI in the physically independent individuals - that is, as results from the power tests decreased for the quadriceps muscle, signs of CI increased. Similarly, Scherder et $\mathrm{al}^{25}$ found that, in older women, quadriceps muscle strength was associated with an improvement in completing function activities, such as attention and working memory. Recently, Boyle et $\mathrm{al}^{27}$ conducted a longitudinal study (3.6 years) and found that individuals with greater muscle strength had a lower risk of coronary heart disease. In addition, for each unit of increase in muscle strength acquired when CI begins, they observed a $43 \%$ reduction in the risk of conversion to AD. More importantly, this association with muscular strength persisted even after adjustments for covariates such as body mass index, physical activity, lung function, vascular risk factors, and genotypes of apolipoprotein E. Lastly, the increase in muscle strength was associated with a lower rate of decline in global cognitive function.

Despite this association between muscular fitness and cognitive function, few studies have examined independently the effect of strength training on cognitive responses. Cassilhas et $\mathrm{al}^{26}$ studied the effect of 6 months of strength training on cognitive function in the elderly. The intervention compared different intensities of strength training and the sample was distributed between moderate intensity ( $50 \%$ one-maximum repetition), high intensity $(80 \%$ one-maximum repetition), and a control untrained group. In terms of muscle strength, both experimental groups performed better than the control group, but no differences were noted between them. In both experimental groups (moderate and high intensity), positive changes were noted in cognitive function.

Further, Liu-Ambrose et $\mathrm{al}^{28}$ investigated the effect of different frequencies of strength training (ie, once or twice weekly) or twice-weekly balance training on changes in cognitive function in older women. Their results demonstrated that 12 months of once- or twice-weekly strength training significantly improved Stroop test performance in cognitively healthy women aged 65-75 years.

Recently, Nagamatsu et $\mathrm{al}^{29}$ demonstrated that 6 months of twice-weekly strength training improved selective attention/ conflict resolution, associative memory, and regional patterns of functional brain plasticity compared with twice-weekly balance exercises. This study provided novel evidence that strength training can benefit multiple domains in those at risk for dementia.

Future research might assess the cost-effectiveness of the exercise interventions for the reduction of $\mathrm{CI}$ in $\mathrm{AD}$; in 2000, the cost of AD and CI treatment in the USA was estimated to be US $\$ 100$ billion. Although there is accumulating evidence for the effectiveness of exercise in combating cognitive decline, there is still a gap in the literature on the indirect and economic costs of physical exercise interventions for $\mathrm{CI}$ and $\mathrm{AD}{ }^{30}$

\section{Limitations}

The results of this review must be interpreted with caution, as the studies reviewed are not conclusive regarding the potential for structured exercise to elicit positive changes in CI and AD. Moreover, another potential limitation of the studies included in this brief review is that most studies presented a small sample size.

\section{Conclusion}

Structured physical exercise (strength and cardiorespiratory exercise) appears to be a promising non-pharmacological strategy for preventing cognitive decline. Individuals with mild or moderate dementia should be more physically active to prevent major losses of physical fitness and function. More studies are needed to delineate the possible mechanisms involved with strength, cardiorespiratory, and other modes of exercise. In addition, future studies with well-controlled designs are needed to address questions regarding the benefits of physical exercise for the prevention and control of dementia.

\section{Disclosure}

The authors declare no conflicts of interest in this work.

\section{References}

1. Querfurth HW, LaFerla FM. Alzheimer's disease. $N$ Engl J Med. 2010;362(4):329-344.

2. Hirtz D, Thurman DJ, Gwinn-Hardy K, Mohamed M, Chaudhuri AR, Zalutsky R. How common are the "common" neurologic disorders? Neurology. 2007;68(5):326-337.

3. Blair SN, Kohl HW 3rd, Barlow CE, Paffenbarger RS Jr, Gibbons LW, Macera CA. Changes in physical fitness and all-cause mortality. A prospective study of healthy and unhealthy men. JAMA. 1995;273(14): 1093-1098.

4. Gordon NF, Kohl HW 3rd, Pollock ML, Vaandrager H, Gibbons LW, Blair SN. Cardiovascular safety of maximal strength testing in healthy adults. Am J Cardiol. 1995;76(11):851-853.

5. Whaley MH, Blair SN. Epidemiology of physical activity, physical fitness and coronary heart disease. J Cardiovasc Risk. 1995;2(4):289-295.

6. Larson EB, Wang L, Bowen JD, et al. Exercise is associated with reduced risk for incident dementia among persons 65 years of age and older. Ann Intern Med. 2006;144(2):73-81.

7. Scarmeas N, Luchsinger JA, Schupf N, et al. Physical activity, diet, and risk of Alzheimer disease. JAMA. 2009;302(6):627-637.

8. Aggarwal NT, Wilson RS, Beck TL, Bienias JL, Bennett DA. Motor dysfunction in mild cognitive impairment and the risk of incident Alzheimer disease. Arch Neurol. 2006;63(12):1763-1769. 
9. Boyle PA, Wilson RS, Buchman AS, et al. Lower extremity motor function and disability in mild cognitive impairment. Exp Aging Res. 2007;33(3):355-371.

10. Franssen EH, Souren LE, Torossian CL, Reisberg B. Equilibrium and limb coordination in mild cognitive impairment and mild Alzheimer's disease. J Am Geriatr Soc. 1999;47(4):463-469.

11. Goldman WP, Baty JD, Buckles VD, Sahrmann S, Morris JC. Motor dysfunction in mildly demented AD individuals without extrapyramidal signs. Neurology. 1999;53(5):956-962.

12. Pettersson AF, Olsson E, Wahlund LO. Effect of divided attention on gait in subjects with and without cognitive impairment. J Geriatr Psychiatry Neurol. 2007;20(1):58-62.

13. Eggermont LH, Gavett BE, Volkers KM, et al. Lower-extremity function in cognitively healthy aging, mild cognitive impairment, and Alzheimer's disease. Arch Phys Med Rehabil. 2010;91(4):584-588.

14. Venturelli M, Scarsini R, Schena F. Six-month walking program changes cognitive and ADL performance in patients with Alzheimer. Am J Alzheimers Dis Other Demen. 2011;26(5):381-388.

15. Colcombe S, Kramer AF. Fitness effects on the cognitive function of older adults: a meta-analytic study. Psychol Sci. 2003;14(2):125-130.

16. Kramer AF, Erickson KI, Colcombe SJ. Exercise, cognition, and the aging brain. J Appl Physiol. 2006;101(4):1237-1242.

17. Burns JM, Cronk BB, Anderson HS, et al. Cardiorespiratory fitness and brain atrophy in early Alzheimer disease. Neurology. 2008;71(3): 210-216.

18. Lautenschlager NT, Cox KL, Flicker L, et al. Effect of physical activity on cognitive function in older adults at risk for Alzheimer disease: a randomized trial. JAMA. 2008;300(9):1027-1037.

19. Baker LD, Frank LL, Foster-Schubert K, et al. Effects of aerobic exercise on mild cognitive impairment: a controlled trial. Arch Neurol. 2010;67(1):71-79.

20. Rolland Y, Pillard F, Klapouszczak A, et al. Exercise program for nursing home residents with Alzheimer's disease: a 1-year randomized, controlled trial. J Am Geriatr Soc. 2007;55(2):158-165.
21. Hernandez SS, Coelho FG, Gobbi S, Stella F. Effects of physical activity on cognitive functions, balance and risk of falls in elderly patients with Alzheimer's dementia. Rev Bras Fisioter. 2010;14(1):68-74. Portuguese.

22. Burns JM, Mayo MS, Anderson HS, Smith HJ, Donnelly JE. Cardiorespiratory fitness in early-stage Alzheimer disease. Alzheimer Dis Assoc Disord. 2008;22(1):39-46.

23. Middleton LE, Barnes DE, Lui LY, Yaffe K. Physical activity over the life course and its association with cognitive performance and impairment in old age. J Am Geriatr Soc. 2010;58(7):1322-1326.

24. Petrella JK, Miller LS, Cress ME. Leg extensor power, cognition, and functional performance in independent and marginally dependent older adults. Age Ageing. 2004;33(4):342-348.

25. Scherder EJ, Eggermont LH, Geuze RH, Vis J, Verkerke GJ. Quadriceps strength and executive functions in older women. Am J Phys Med Rehabil. 2010;89(6):458-463.

26. Cassilhas RC, Viana VA, Grassmann V, etal. The impact of resistance exercise on the cognitive function of the elderly. Med Sci Sports Exerc. 2007;39(8):1401-1407.

27. Boyle PA, Buchman AS, Wilson RS, Leurgans SE, Bennett DA. Association of muscle strength with the risk of Alzheimer disease and the rate of cognitive decline in community-dwelling older persons. Arch Neurol. 2009;66(11):1339-1344.

28. Liu-Ambrose T, Nagamatsu LS, Graf P, Beattie BL, Ashe MC, Handy TC. Resistance training and executive functions: a 12-month randomized controlled trial. Arch Intern Med. 2010;170(2): $170-178$.

29. Nagamatsu LS, Handy TC, Hsu CL, Voss M, Liu-Ambrose T. Resistance training promotes cognitive and functional brain plasticity in seniors with probable mild cognitive impairment. Arch Intern Med. 2012;172(8):666-668.

30. Davis JC, Hsiung GY, Liu-Ambrose T. Challenges moving forward with economic evaluations of exercise intervention strategies aimed at combating cognitive impairment and dementia. Br J Sports Med. 2011 45(6):470-472.
International Journal of General Medicine

\section{Publish your work in this journal}

The International Journal of General Medicine is an international, peer-reviewed open-access journal that focuses on general and internal medicine, pathogenesis, epidemiology, diagnosis, monitoring and treatment protocols. The journal is characterized by the rapid reporting of reviews, original research and clinical studies across all disease areas.

\section{Dovepress}

A key focus is the elucidation of disease processes and management protocols resulting in improved outcomes for the patient.The manuscript management system is completely online and includes a very quick and fair peer-review system. Visit http://www.dovepress.com/ testimonials.php to read real quotes from published authors. 